Article

\title{
Analysis of the Pyrolytic Behaviour of Birch, Maple, and Rowan Leaves
}

\author{
Valentina Zubkova *(D), Andrzej Strojwas (D) and Marcin Bielecki (D) \\ The Institute of Chemistry, Jan Kochanowski University, Uniwersytecka Str. 7, 25-369 Kielce, Poland; \\ andrzej.strojwas@ujk.edu.pl (A.S.); marcin-bielecki-1994@wp.pl (M.B.) \\ * Correspondence: zubkova@ujk.edu.pl or walentyna.zubkowa@ujk.edu.pl
}

check for

updates

Citation: Zubkova, V.; Strojwas, A.; Bielecki, M. Analysis of the Pyrolytic Behaviour of Birch, Maple, and Rowan Leaves. Energies 2021, 14, 2091 https://doi.org/10.3390/en14082091

Academic Editor: Biagio Morrone

Received: 25 February 2021

Accepted: 6 April 2021

Published: 9 April 2021

Publisher's Note: MDPI stays neutral with regard to jurisdictional claims in published maps and institutional affiliations.

Copyright: (c) 2021 by the authors. Licensee MDPI, Basel, Switzerland. This article is an open access article distributed under the terms and conditions of the Creative Commons Attribution (CC BY) license (https:// creativecommons.org/licenses/by/ $4.0 /)$.

Abstract: A research study was conducted on the thermal behaviour of leaves of urban greenery (birch, maple, and rowan) and the products of their pyrolysis and extraction as assisted by microwaves. The obtained products of pyrolysis and extraction were investigated with the use of FT-IR and UV spectroscopies and XRD techniques. A contractive analysis of samples of chars, condensates, after-extraction residue, and extracts showed that the changes in structural-chemical parameters of leaves of different types of trees during pyrolysis and extraction take place in distinct ways. About $22 \%$ of material was removed from birch leaves during extraction, and more than $17 \%$ of material was extracted from maple and rowan leaves. It was determined that, during pyrolysis of after-extraction residue of leaves, many fewer PAH compounds with carbonyl groups along with alcohols and phenols are emitted than during pyrolysis of non-extracted leaves. Taking into account that pyrolysis is the first stage of combustion, a decrease in the amount of dangerous compounds in the volatile products of pyrolysis leads to a lower contribution of such compounds in combustion products. This indicates that leaves of urban greenery can be subjected to combustion after extraction, and the obtained extracts can be used as a source of phytochemicals and chemical reagents.

Keywords: leaves; pyrolysis; extraction; TG/FT-IR; XRD; UV-spectroscopy

\section{Introduction}

Tree leaves falling in autumn are considered urban green waste. The green waste is not classified as hazardous waste. Nonetheless, their accumulation in the place of origin is harmful to the environment and requires special disposal. Tree leaves have diverse and complex composition. Phenol, flavonoid and flavan-3-ol, 2,2-diphenyl-1-picrylhydrazyl, and 2,2-azino-bis(3-ethylbenzothiazoline-6-sulphonic acid) have been identified in their composition [1]. Plant leaves can be used to obtain phytochemicals (polyphenols and triterpenoids) [2] and bioactive antioxidant compounds such as oleuropein and luteolin. Eucalyptol, a chemical compound present in eucalyptus leaves, was found in bio-oils from leaves in high concentration [3]. The leaves of Polyalthia longifolia [4] and olive trees [3] can be successfully applied to produce bio-oils.

Other applications of leaves are widely known. Mango leaves can be used for production of quantum dots [5] and biochars from orchid tree leaves can be utilized as "fuel of a direct carbon solid oxide fuel cell" [6]. Attempts have also been made to include tree leaves in the composition of forage for mature male sheep [7]. Moreover, biochars from banana tree leaves can be used for the production of construction insulating material [8]. Celtuce leaves are used for the production of porous coal with "outstanding supercapacitance and $\mathrm{CO}_{2}$ capture performance" [9], and activated ginkgo-leaf-derived carbons were analysed as a source of porous carbons made of cheap biomass that can be applied as supercapacitor electrode materials in the acid electrolyte [10]. Carbon materials from bamboo leaves in combination with copper oxide/cuprous oxide nanoparticles can serve as a supercapacitor [11], and batat leaves can be used to obtain three-dimensionally interconnected carbon nanorings [12]. 
Composting is the most widespread and known way of utilizing the leaves of garden trees $[13,14]$. However, the leaves of urban trees contain large amounts of heavy metals because of their close proximity to roads [15-18] and therefore cannot be used for soil fertilization. Limitation of the use of fossil fuels makes us pay attention to tree leaves as a lignocellulosic biomass that can be applied for energy purposes [19]. According to Makkawi et al., the leaves of Phoenix dactylifera along with other wastes arising from its cultivation can be converted into energy without any harm to the environment or costs for disposal of these wastes [20]. Nevertheless, it is believed that forest waste has a much lower parameter of high heating value (HHV) compared to agricultural waste [21]. Despite this, tree leaves can be used as components of pellets applied in commercial devices [22]. According to He et al. [3], eucalyptus leaves can be used for energy purposes. It is characteristic of leaves that they behave differently from the wood of the same species: "leaves tend to give a higher yield of char and a lower yield of organics in bio-oil than the wood" [3].

A serious problem arising during combustion is the formation of ash and the emission of suspended dust along with volatile organic compounds, including terpenoids [23-25]. An analysis of the composition of suspended dust proved that coal atoms prevail in its elemental composition. According to transmission electron microscope (TEM) investigations, the composition of coal atoms corresponds to the presence of fringes formed due to pyrolysis and the combustion of compounds containing aromatic hydrocarbons [26,27]. This gives reasons to suggest that hydrocarbons in the composition of volatile pyrolysis products (as the first stage of combustion) along with inorganic particles lead to the formation of suspended dust.

In order to verify the aforementioned statements and to propose a more economical way to dispose of leaves from selected tree types of urban greenery, the following aims were set:

(i) to investigate the course of the pyrolysis process of birch, maple, and rowan tree leaves using a pyrolytic oven manufactured by the Czylok company and a thermogravimetric Fourier transform-infrared (TG/FT-IR) measuring unit;

(ii) to compare structural-chemical parameters of the pyrolysis products of birch, maple, and rowan samples;

(iii) to determine the extraction yield of birch, maple, and rowan samples and to investigate the obtained products of extraction using the techniques of Fourier transforminfrared (FT-IR) and ultraviolet (UV) spectroscopies and X-ray diffraction (XRD).

\section{Materials and Methods}

The objects of the research were birch leaves (BL), maple leaves (ML), and rowan leaves (RL). These tree species are among the most common ones in Polish urban greenery. The washed leaves were dried at a temperature of $105^{\circ} \mathrm{C}$ and ground to a diameter of particles $<3 \mathrm{~mm}$. The elemental analysis of samples was carried out in a CHNS Elementar Vario Micro Cube analyzer. The results of elemental analysis and the values of HHV parameters of the studied samples are presented in Table 1.

Table 1. The main characteristics of leaves.

\begin{tabular}{cccc}
\hline Main Characteristics & BL & ML & RL \\
\hline C [\%] & $49.39 \pm 0.21$ & $41.99 \pm 1.02$ & $48.55 \pm 0.04$ \\
H [\%] & $6.97 \pm 0.05$ & $5.71 \pm 0.03$ & $6.69 \pm 0.05$ \\
[ [\%] & $0.78 \pm 0.71$ & $1.46 \pm 0.03$ & $1.33 \pm 0.07$ \\
\hline S [\%] & $0.06 \pm 0.05$ & $\mathrm{a}$ & $0.07 \pm 0.01$ \\
$\mathrm{O}^{\mathrm{a}}[\%]$ & $34.42 \pm 0.22$ & $34.49 \pm 0.28$ & $33.05 \pm 0.04$ \\
A [\%] & $8.38 \pm 0.06$ & $16.35 \pm 0.02$ & $10.32 \pm 0.02$ \\
$\mathrm{HHV}^{\mathrm{b}}[\mathrm{MJ} / \mathrm{Kg}]$ & $21.72 \pm 0.22$ & $17.46 \pm 0.28$ & $21.19 \pm 0.04$
\end{tabular}

(a) Calculated by difference, $\mathrm{O}[\%]=100-\mathrm{C}-\mathrm{H}-\mathrm{N}-\mathrm{S}-\mathrm{Ash}$; ${ }^{(\mathrm{b})}$ Calculated by HHV $\left[\mathrm{MJ} \mathrm{kg}^{-1}\right]=0.3491{ }^{*} \mathrm{C}+$ $1.1783 * \mathrm{H}+0.1005 * \mathrm{~S}-0.0151 * \mathrm{~N}-0.1034 * \mathrm{O}-0.0211^{*}$ Ash; a-absent; BL-birch leaves; ML-maple leaves; RL-rowan leaves. 
Table 2 presents the results of the determination of the content of inorganic elements in the samples. This determination was made using elemental analysis with the energy dispersive X-ray fluorescence (ED-XRF) technique, using a Niton XL3T Goldd+ analyzer manufactured by Thermo Fisher Scientific Inc (Waltham, MA, USA).

Table 2. Content of inorganic elements.

\begin{tabular}{cccc}
\hline Elements & BL & ML & RL \\
\hline $\mathrm{Ca}[\%]$ & $2.39 \pm 0.02$ & $3.06 \pm 0.02$ & $3.92 \pm 0.03$ \\
$\mathrm{~K}[\%]$ & $3.30 \pm 0.03$ & $1.64 \pm 0.02$ & $1.84 \pm 0.02$ \\
$\mathrm{Fe}[\mathrm{mg} / \mathrm{kg}]$ & $125 \pm 18$ & $231 \pm 21$ & $579 \pm 28$ \\
$\mathrm{P}[\mathrm{mg} / \mathrm{kg}]$ & $603 \pm 115$ & $2999 \pm 118$ & $1152 \pm 133$ \\
$\mathrm{~S}[\mathrm{mg} / \mathrm{kg}]$ & $2475 \pm 94$ & $1707 \pm 71$ & $3563 \pm 106$ \\
$\mathrm{Si}[\mathrm{mg} / \mathrm{kg}]$ & $2129 \pm 133$ & $2224 \pm 114$ & $11,577 \pm 227$ \\
$\mathrm{Sr}[\mathrm{mg} / \mathrm{kg}]$ & $38 \pm 1$ & $78 \pm 1$ & $99 \pm 2$ \\
$\mathrm{Zn}[\mathrm{mg} / \mathrm{kg}]$ & $98 \pm 6$ & $12 \pm 3$ & $27 \pm 4$ \\
\hline
\end{tabular}

It follows from Table 2 that the greatest amount of determined inorganic elements (apart from K atoms) was observed in the RL sample.

The biomass samples were pyrolyzed in a PRC $70 \times 708 / 110 \mathrm{M}$ pipe oven manufactured by the Czylok company under the atmosphere of nitrogen of $99.999 \%$ purity. The heating rate in the oven was $10{ }^{\circ} \mathrm{C} / \mathrm{min}$. The samples were heated to a temperature of $450{ }^{\circ} \mathrm{C}$. The volatile pyrolysis products were removed to a retort with methanol cooled by water with ice to obtain a condensate, i.e., the volatile products of pyrolysis absorbed by methanol. Dried samples weighing $2 \mathrm{~g}$ were extracted with a mixture of chloroform and methanol (25:25 mL) in an Anton Paar multiwave 3000 microwave extractor at a temperature of $150{ }^{\circ} \mathrm{C}$ under the pressure of 18 bars for $20 \mathrm{~min}$. After the solvent evaporated, the samples of extracts and after-extraction residues (samples RBL, RML, and RRL) were subjected to further analysis.

The samples of initial biomass (BL, ML, RL) and after-extraction residues (RBL, RML, RRL) were pyrolyzed in a TG/FT-IR unit under the atmosphere of nitrogen of high purity up to a temperature of $780{ }^{\circ} \mathrm{C}$ in order to determine the composition of volatile products of pyrolysis being formed. The volatile products were directed via interface to a Nicolet iS10 spectrometer, and their FT-IR spectra were registered in the range of a wavenumber of 4000-600 1/cm. The FT-IR spectra were elaborated and the deconvolution of differential thermogravimetric (DTG) curves was performed using OMNIC9 software. During deconvolution, a fragment of the DTG curve was analysed in the range of $20-600{ }^{\circ} \mathrm{C}$.

The samples of biomass, chars, condensates, and extracts were studied by the attenuated total reflectance (ATR) technique using a Thermo Fischer Scientific Nicolet iS10 spectrometer. For this purpose, a Smart MIRacle module with a ZnSe monocrystal was used. The automatic correction of baseline was performed by OMNIC9 software, taking into account the local optical minima near 2400, $20001 / \mathrm{cm}$. The UV spectra of the samples of condensates and extracts dissolved in acetonitrile were registered by a Jasco UV-Vis $\mathrm{V}-630$ spectrophotometer in the range of wavelength of 195-350 nm. For this purpose, $0.0001 \mathrm{~g}$ was taken from the samples and dissolved in $50 \mathrm{~mL}$ of acetonitrile. The dissolved samples were investigated in quartz cuvettes. The obtained spectra were normalized and deconvoluted using Jasco Spectra Manager software.

The biochars were heated in a pyrolytic oven at a temperature of $450{ }^{\circ} \mathrm{C}$ and investigated with the use of $\mathrm{X}$-ray diffraction. Using $\mathrm{Cu}_{\mathrm{k} \alpha}$ radiation, the powder diffractograms were recorded. The $X$-ray lamp mode was $\mathrm{U}=40 \mathrm{kV}, \mathrm{I}=25 \mathrm{~mA}$, and the exposure time at every spot was $20 \mathrm{~s}$. 


\section{Results and Discussion}

\subsection{Analysis of Pyrolysis Products}

Table 3 presents the yields of char and condensate obtained during pyrolysis of the samples of leaves.

Table 3. Yield of chars and condensates obtained during pyrolysis of samples.

\begin{tabular}{ccc}
\hline Sample & Yield of Char [\%] & Yield of Condensate [\%] \\
\hline BL & 33.8 & 4.1 \\
ML & 41.8 & 1.9 \\
RL & 35.1 & 3.1 \\
\hline
\end{tabular}

It follows from Table 3 that at a temperature of $450^{\circ} \mathrm{C}$, the ML sample had the greatest char yield, and the BL sample had the lowest one.

Figure 1 presents the ATR spectra of the dried samples of leaves. The spectra coincided in such a way that the height of the band near $16001 / \mathrm{cm}$ was the same. This height corresponds to the presence of bonds of the $\mathrm{C}=\mathrm{C}$ type in the material of samples.

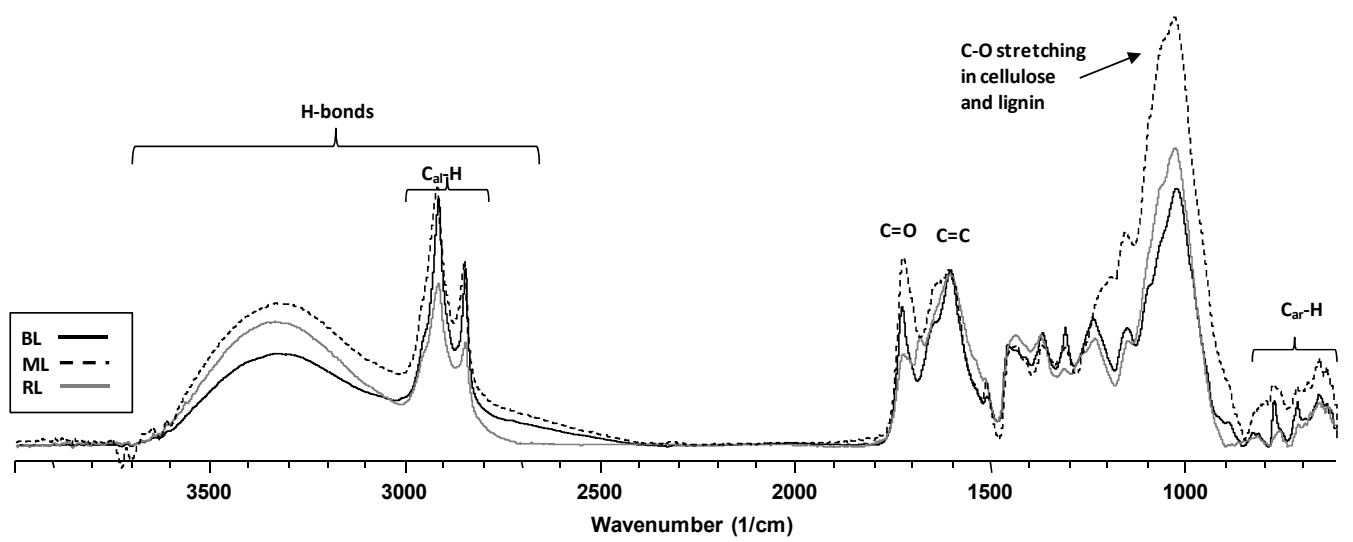

Figure 1. ATR spectra of examined leaves.

This enables a visual estimation of the contribution of particular bonds and groups of atoms with respect to the content of $\mathrm{C}=\mathrm{C}$ bonds in the studied samples. The shape of the curves in Figure 1 implies that the samples varied from each other by a contribution ratio of hydrogen bonds, bonds of the $\mathrm{C}_{\mathrm{al}}-\mathrm{H}$ type, carbonyl groups, and bonds of the $\mathrm{C}_{\mathrm{ar}}-\mathrm{H}$ type. However, the most noticeable difference is the contribution of $\mathrm{C}-\mathrm{O}$ stretching in cellulose and lignin in the samples.

For comparison, Figure 2 presents the ATR spectra of initial samples of leaves as well as their condensates and chars. The ATR spectra of the samples (except the BL condensate sample) were normalized with respect to the height of the band near $16001 / \mathrm{cm}$.

In the ATR spectra of all samples, there were some wide bands in the range of wavenumbers of $3700-24001 / \mathrm{cm}$. These bands point to the presence of $-\mathrm{OH}$ groups that form a range of hydrogen bonds $(\mathrm{OH} \cdots \pi$, self-associated $\mathrm{OH}, \mathrm{OH} \cdots \mathrm{OR}$, tightly bound cyclic $\mathrm{OH}$-tetramers, $\mathrm{OH} \cdots \mathrm{N}$, carboxylic acids dimmers, $\mathrm{SH} \cdots \mathrm{N})[28,29]$ in the studied samples and to the bonds of the $\mathrm{C}_{\mathrm{al}}-\mathrm{H}$ type (range of wavenumbers of 2950-2850 1/cm). The ATR spectra suggest that $>C=O$ groups (range of wavenumbers of 1800-1650 1/cm) are present in the initial samples and condensates, and $C=C$ groups (near $16001 / \mathrm{cm}$ ) are present in the initial samples, condensates (except the BL sample), and chars. In the dactyloscopic range, in the ATR spectra there are visible one to eight bands that are characteristic of groups occurring in cellulose, hemicellulose, and lignin [30-32]. The assignment of the bands is explained in the caption for Figure 2. Near the wavenumber of $10301 / \mathrm{cm}$, there is an intensive band of $\beta-1,4$-glycoside bond (marked as 9 in the figure). The presence of 
the aforementioned bands shows that the studied samples of leaves should be rated as lignocellulose biomass [31-33]. The spectra in Figure 2 suggest that the height of band nine, corresponding to the presence of $\mathrm{C}-\mathrm{O}$ stretching (in cellulose and lignin) in the samples, decreased during the pyrolysis process. This implies that this $\beta-1,4$-glycoside bond underwent degradation: the height of band nine decreased in char of the BL sample by five times, in char of the ML sample by three times, and in char of the RL sample by 2.5 times. As a result of pyrolysis, the contribution ratio of the bonds of the $\mathrm{C}_{\mathrm{al}}-\mathrm{H}$ type decreased in all chars. Moreover, the bands corresponding to the presence of carbonyl groups disappeared. The contribution ratio of hydrogen bonds decreased in the chars of ML and RL. In all chars of the studied samples in the range of 1450-1350 1/cm, there appeared a wide band three, which can be attributed to aromatic skeletal vibration combined with $\mathrm{CH}$ in plane deformation for lignin and cellulose along with $\mathrm{CH}$ deformation in fragments of cellulose and hemicellulose [32].

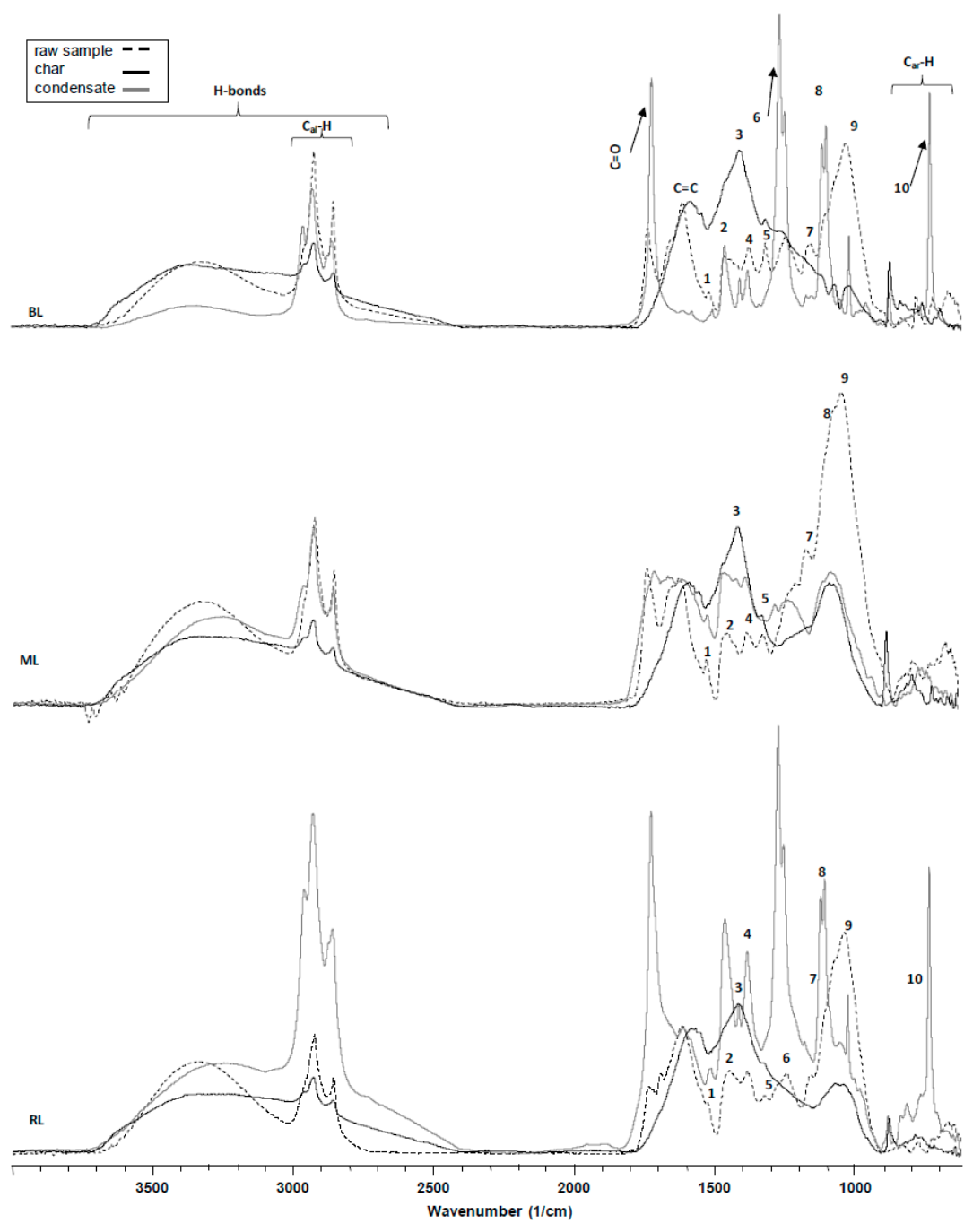

Figure 2. ATR spectra of examined samples and their pyrolysis products-chars and condensates: (1) aromatic skeletal vibrations of guaiacyl rings; (2) pyran ring symmetric scissoring C-H deformation, asymmetric in-plane for lignin and hemicellulose; (3) aromatic skeletal vibration combined with C-H in-plane deformation of cellulose; (4) C-H deformation in hemicellulose; (5) C-O vibration in syringil and guaiacyl rings; (6) guaiacyl ring breathing, C-O stretch in lignin, C-O linkage in guaiacyl aromatic methoxyl groups; (7) $\mathrm{C}-\mathrm{O}-\mathrm{C}$ stretching vibration ring skeletal pyranose; (8) $\mathrm{C}-\mathrm{O}$ stretching in cellulose; (9) C-O stretching in cellulose; (10) C-H out-of-plane glucose ring in cellulose and hemicellulose or 1-2-disubstituted aromatic rings [30-33]. 
The bands present in the spectra of condensates correspond to the disappearance of the aforementioned bands in the spectra of chars. Figure 2 shows that there is a high contribution ratio of the bands corresponding to the presence of bonds of the Cal- $\mathrm{H}$ type, the bands corresponding to aromatic C-H out-of-plane bend in the range of 900-600 1/cm, and other bands one to nine, characteristic of dactyloscopic range of biomass in the composition of condensates (for explanation, see figure caption). Special attention should be given to band 10 in the condensates of the BL and RL samples, which correspond to the presence of the bond of $\mathrm{C}-\mathrm{H}$ bending in 1,2-disubstituted aromatics in these samples. It is important to mention the fact that the contribution ratio of polar compounds able to form hydrogen bonds in the condensates of the ML and RL samples increased in comparison to their biochars. In contrast to the BL and RL samples, no substantial increase in the contribution ratio of carbonyl groups was observed in the condensate of the ML sample.

The spectra of the initial samples of leaves and the products of their pyrolysis presented in Figure 2 show that the differences in contribution ratio of particular groups of atoms in initial samples of different leaves also cause differences in the contribution ratio of these groups in condensates and biochars. In the condensates of samples, there are some compounds able to form hydrogen bonds and compounds with polar groups. This implies that there can be intermolecular interactions, leading to self-aggregation of these compounds in volatile products and to the formation of aerosol particles. Taking into account that pyrolysis is the first stage of the combustion process, it can be presumed that these aerosol particles will form particles of suspended dust and additionally poison the environment. To describe the observed differences in composition of the condensates in Figure 2, UV spectroscopy was included in the analysis.

Figure 3 presents the UV spectra of the condensate material of the BL, RL, and ML samples.

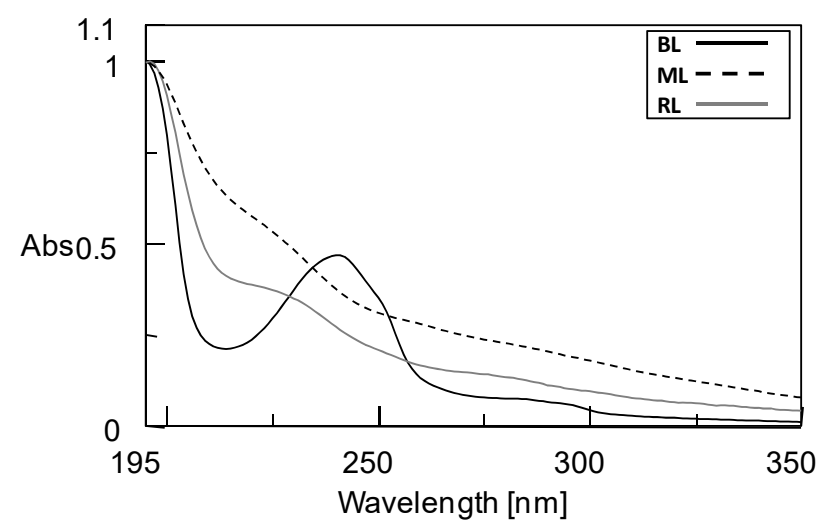

Figure 3. UV spectra of obtained condensates.

Similar to the ATR spectra, the UV spectra of condensates have different shapes, which implies differences in their composition. These differences concern the presence of compounds containing chromophore groups. The condensate of the ML sample has the greatest value of absorbance in the entire discussed range of wavelengths $(195-350 \mathrm{~nm})$. This suggests that there is a greater concentration of the mixture of various compounds with chromophore groups in this condensate. The condensate of the BL sample is a more homogeneous material with respect to the occurrence of compounds with particular chromophore groups. In the spectrum of this condensate near $235 \mathrm{~nm}$, there is a distinct maximum, which implies the presence of a prevailing amount of compounds of the same type. In the ATR spectrum of the condensate of the BL sample, there is no band near $16001 / \mathrm{cm}$; however, in the ATR spectra of the RL and ML samples, such a band is visible (see Figure 2). This implies a greater homogeneity of the material of the BL condensate. On the basis of the ATR spectra of this condensate (Figure 2), it can be suggested that the compounds with carbonyl chromophore group in the acyclic aliphatic compounds prevail in its composition [34]. 


\subsection{Analysis of Extraction Products}

The studied samples of leaves were extracted in order to explain other details about their composition. Table 4 presents the results of the extraction of dried samples of leaves. The data in this table imply that the birch tree has the largest amount of the material soluble in a mixture of chloroform and methanol under extraction conditions.

Table 4. Yield of material soluble in mixture of chloroform and methanol and yield of residual material.

\begin{tabular}{ccc}
\hline Sample & $\begin{array}{c}\text { Yield of Extract Calculated from } \\
\text { the Mass of the Extract [\%] }\end{array}$ & $\begin{array}{c}\text { Yield of Extract Calculated } \\
\text { from the Mass of the } \\
\text { After-Extraction Residue [\%] }\end{array}$ \\
\hline BL & $22.12 \pm 0.20$ & $24.13 \pm 1.74$ \\
ML & $17.20 \pm 0.03$ & $17.93 \pm 1.77$ \\
RL & $17.78 \pm 1.30$ & $19.26 \pm 2.12$ \\
\hline
\end{tabular}

Figure 4 presents the ATR spectra of extracts and after-extraction residues of leaves normalized with regard to the $\mathrm{C}=\mathrm{C}$ band near $16001 / \mathrm{cm}$. For better comparison, the spectra of initial samples are presented by a dotted line. The assignment of bands one to five in the ATR spectrum is explained in the figure caption. Attention should be drawn to the fact that the $\beta-1,4-$ glycoside bond, giving band six in the spectra near $1030 \mathrm{~cm}^{-1}$, underwent degradation as a result of extraction. The relative height of this band decreased in the after-extraction residue but increased in the extract. This implies that the part of the material of leaves that contained this bond was extracted. The analysis of the spectra in Figure 4 shows that, in the extracts, after-extraction residue, and initial samples there occur some bands near the same wavenumbers. Hence, it can be suggested that the same groups of atoms occur in these samples. However, the contribution ratios of these groups of atoms and bonds in the formation of the ATR spectra of the discussed samples are different.

The contribution ratio of hydrogen bonds in the RBL sample is lower, whereas in the RRL sample it is higher than in initial samples. In the RML sample, the contribution ratio of hydrogen bonds in the after-extraction residue and initial sample is the same. Attention should be drawn to the fact that, similar to the condensates, the samples of BL, ML, and RL have a high contribution ratio of carbonyl groups. However, the compounds, the presence of which in the spectra causes the occurrence of bands in the range of somehow greater values of wavenumbers, prevail in the extracts of the BL and ML samples. These can be esters $(1750-17351 / \mathrm{cm})$, carboxyl acids $(17601 / \mathrm{cm})$, aldehydes $(1740-17201 / \mathrm{cm})$, and aliphatic ketones $(1725-17051 / \mathrm{cm})$. In the extract of the RL sample (the bands in the area of somehow higher values of wavenumbers), the presence of dimmers of conjugated acid (1710-1680 1/cm), conjugated aldehyde (1710-16851/cm), and conjugated ketone (1685-1666 1/cm) should be expected [35].

The discussed results show that there is some material moved out as a result of the microwave extraction of leaves. The compounds able to form hydrogen bonds and the compounds with carbonyl groups are removed together with this material. The contribution ratio of almost all functional groups decreases in the after-residue extract. This implies that extraction before pyrolysis makes it possible to decrease the content of hydrocarbons hazardous to the environment in the composition of volatile products of pyrolysis. Ipso facto, the contribution of hazardous compounds in the composition of combustion products emitted to the environment will be decreased. However, the obtained material of extracts after fractionation can be used as a source of platform chemicals. 

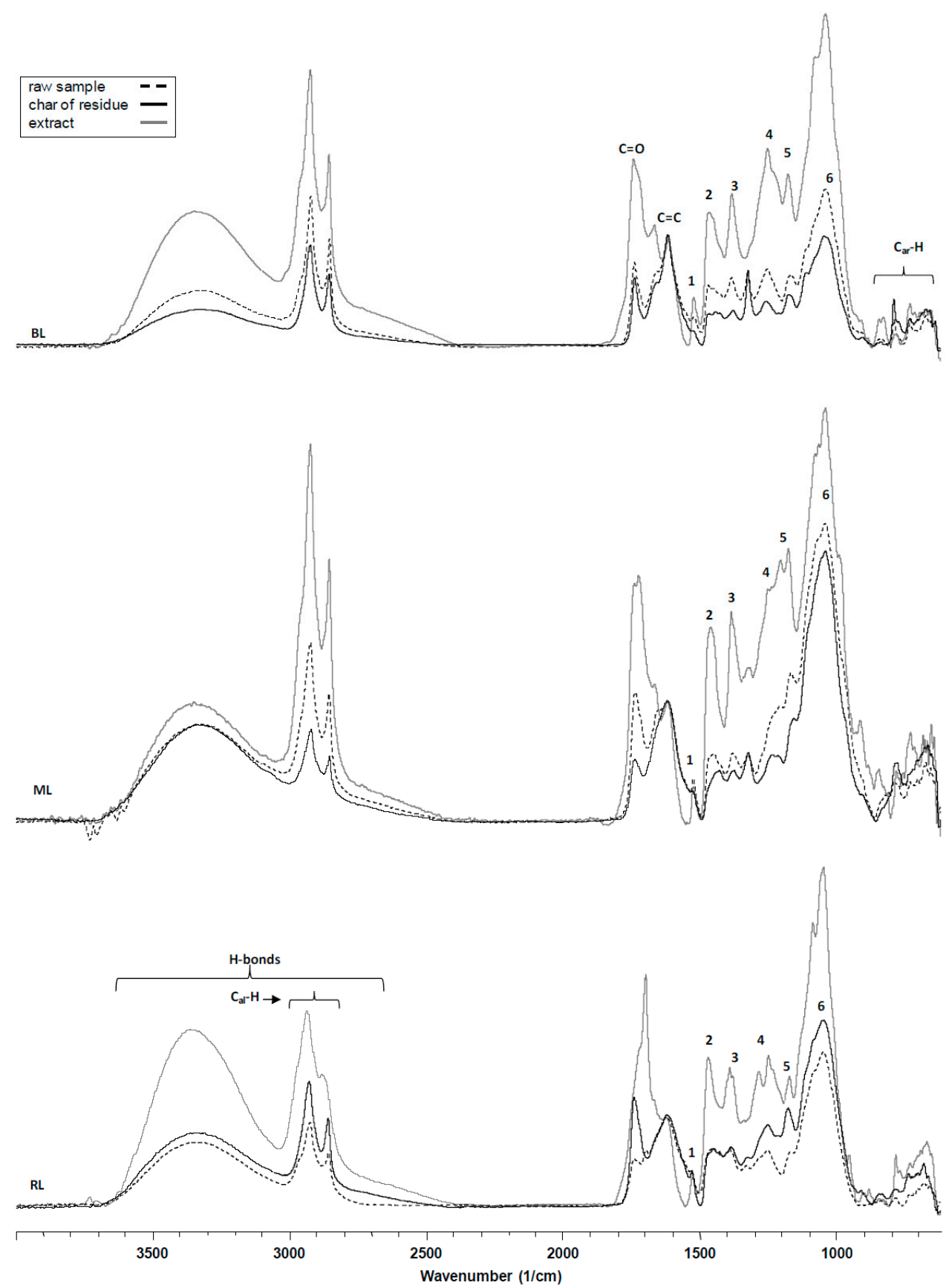

Figure 4. ATR spectra of examined samples and their extraction products—extracted and residual materials: (1) aromatic skeletal vibrations of guaiacyl rings; (2) pyran ring symmetric scissoring $\mathrm{C}-\mathrm{H}$ deformation, asymmetric in plane for lignin and hemicellulose; (3) C-H deformation in hemicellulose; (4) guaiacyl ring breathing, C-O stretch in lignin, C-O linkage in guaiacyl aromatic methoxyl groups; (5) C-O-C stretching vibration ring skeletal pyranose; (6) C-O stretching in cellulose and C-O deformation [31-33,36].

Figure 5 shows the UV spectra of the material extracted from the initial samples of leaves. 


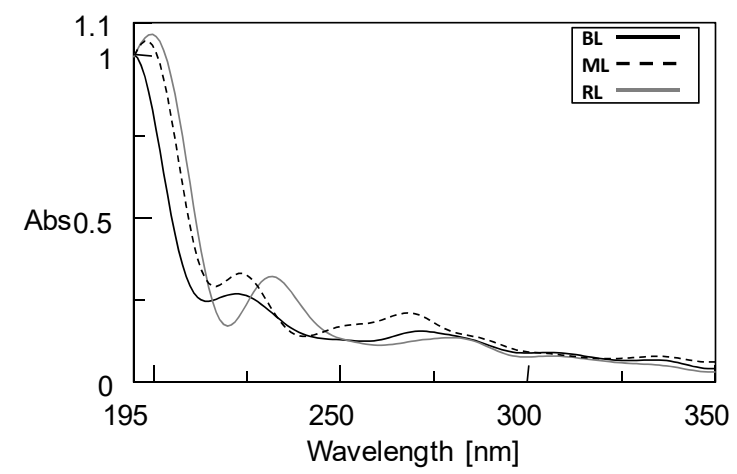

Figure 5. UV spectra of extracted material.

The presence of distinct maxima in the UV spectra of extracts (Figure 5) implies that there are certain classes of chemical compounds with similar chromophore groups occurring in the composition of extracts of the studied samples but not a mixture of various chemical compounds (what can be suggested on the basis of the shape of spectra of the RL and ML samples as seen in Figure 3). This fact will make the separation of extract material into particular fractions easier.

\subsection{Analysis of Pyrolysis Process in a TG/FT-IR Unit}

Figure 6a presents the TGA and DTG curves of BL initial samples and their afterextraction residues.

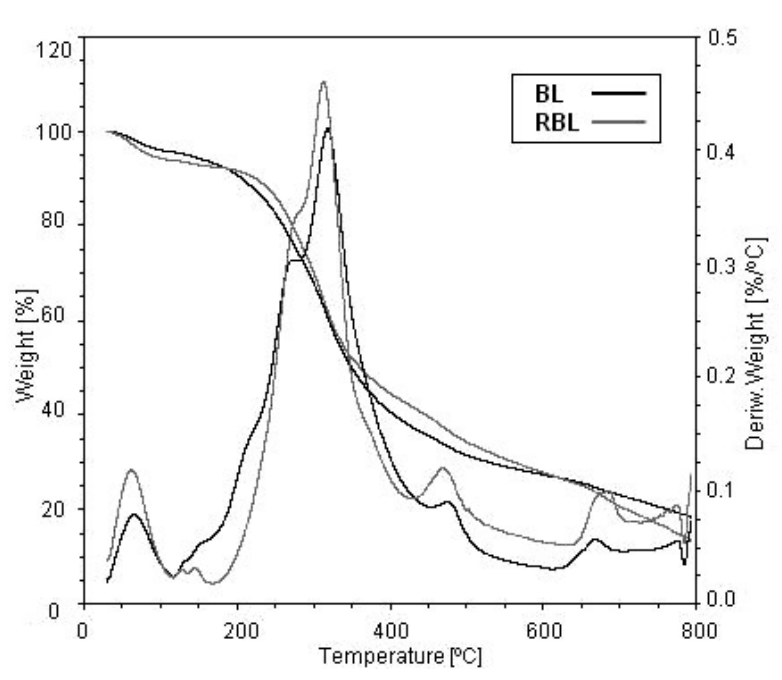

(a)

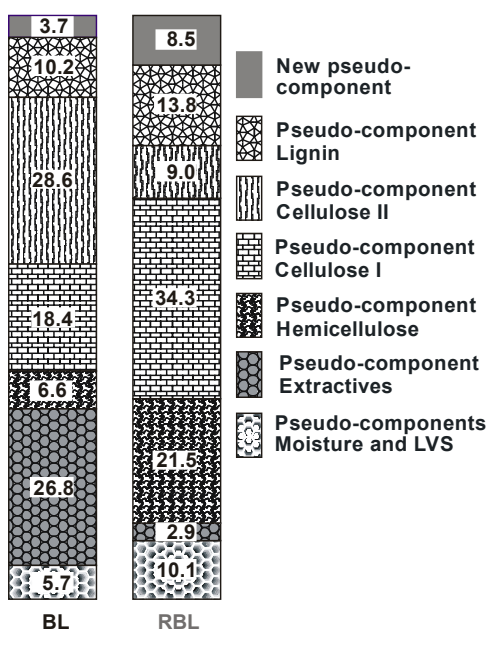

(b)

Figure 6. TGA and DTG curves (a) along with the results of deconvolution of the DTG curve (b) of BL and RBL samples.

The results of deconvolution of the DTG spectra are seen in Figure $6 \mathrm{~b}$. The curves of mass loss in Figure 6a imply that the RBL sample in the temperature range of $200-600{ }^{\circ} \mathrm{C}$ has an inclination towards a yield in volatile products of pyrolysis lower than the BL sample. However, in the temperature range of $270-320^{\circ} \mathrm{C}$ and higher than $430{ }^{\circ} \mathrm{C}$, it shows a greater mass loss rate. In case of the RBL sample, the mass loss rate decreased after extraction in the ranges of $120-260{ }^{\circ} \mathrm{C}$ and $320-420^{\circ} \mathrm{C}$, but at the temperatures of $260-320^{\circ} \mathrm{C}$ and higher than $430^{\circ} \mathrm{C}$, it increased. This implies that during extraction not only were some components that underwent decomposition at lower temperatures removed from the BL sample, but the structure of material of the entire sample loosened. On the basis of thermogravimetric studies presented in works $[37,38]$, the temperature ranges were established in which basic components of biomass (hemicellulose, cellulose, and lignin) 
should undergo decomposition during pyrolysis. The deconvolution of the DTG curves of BL and RBL samples was carried out taking into account these temperature ranges. It follows from the comparison of shape of the DTG curves of samples that, during extraction of $\mathrm{BL}$, the extractives in the composition of volatiles were removed as the first from the sample. The contribution of these extractives during pyrolysis of RBL decreased by almost 9.5 times (Figure $6 \mathrm{~b}$ ). The contribution of pseudo-components of moisture and light volatile substances (LVS) increased during pyrolysis. Attention should be drawn to an increase in contribution of the pseudo-components of hemicellulose and cellulose I and a decrease in contribution of cellulose II in the formation of the DTG curve. This implies that, under the influence of microwave extraction and an increased pressure, there occur destabilization and loosening of the structure of hemicellulose, cellulose, and lignin of the BL sample, which caused a decrease in their thermal stability. The contribution of a new pseudocomponent in the formation of the DTG curve of the RBL sample increased. In work [3], the authors stated that the course of pyrolysis of leaves of forest trees differs from the course of pyrolysis of wood of the same species. In the DTG curves near the temperatures of 470 and $675^{\circ} \mathrm{C}$, there appear some peaks. The presence of these peaks can be caused by interactions between cellulose and lignin $[39,40]$ or lignin and hemicellulose [41,42]. The course of interaction of the inorganic components on the surface of char with the volatile products of the pyrolysis of leaves cannot be excluded [43]. These interactions could have caused the formation of the new products, the decomposition of which contributed to the increase in mass loss rate at the temperatures of 470 and $675^{\circ} \mathrm{C}$ and the formation of maxima visible in the DTG curve.

Figure 7a presents the thermogravimetric curves and the results of deconvolution of the DTG curve of ML and RML samples (Figure 7b).

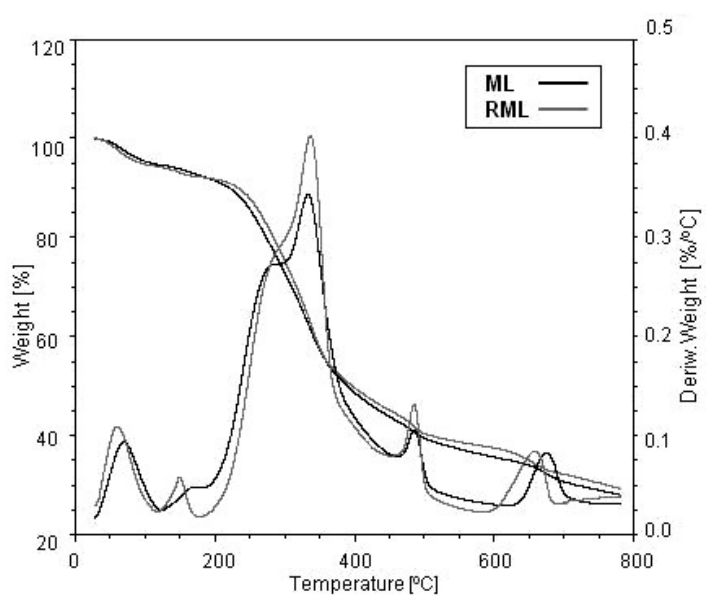

(a)

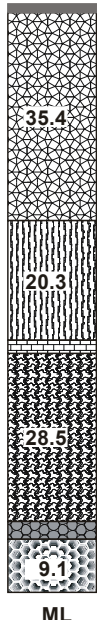

ML

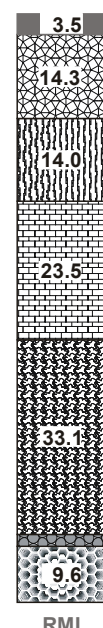

RML

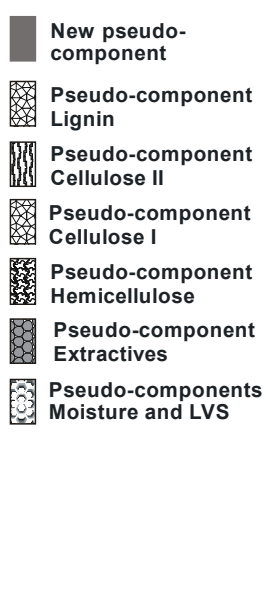

(b)

Figure 7. TGA and DTG curves (a) along with the results of deconvolution of the DTG curve (b) of ML and RML samples.

It follows from comparison of the curves of mass loss of ML and RML samples in Figure 7a that the extraction did not substantially influence the course of the pyrolysis process of the RML sample. The rate of removal of volatile products from the RML sample decreased in the temperature ranges of $170-275^{\circ} \mathrm{C}$ and $360-610^{\circ} \mathrm{C}$ and increased in the temperature range of $270-360^{\circ} \mathrm{C}$. The results of deconvolution in Figure $7 \mathrm{~b}$ proved that the extraction did not cause any significant changes in contribution of extractives, moisture, and LVS. However, it increased the removal of hemicellulose from the RML sample by $4.6 \%$, the removal of cellulose I by $3 \%$, and the removal of cellulose II by almost $12 \%$. As a result of the extraction, the removal of volatile products corresponding to lignin pseudo-components decreased by almost $20 \%$. 
Figure 8 presents the TGA and DTG curves of RL and RRL samples and the results of deconvolution of the DTG curves of these samples.

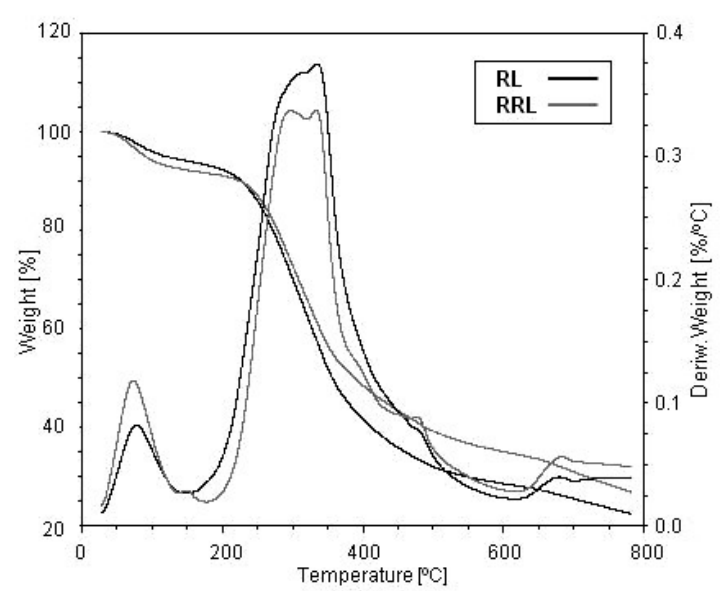

(a)

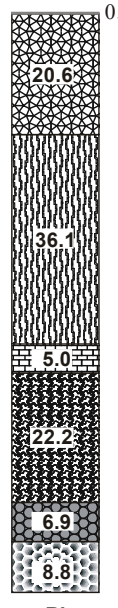

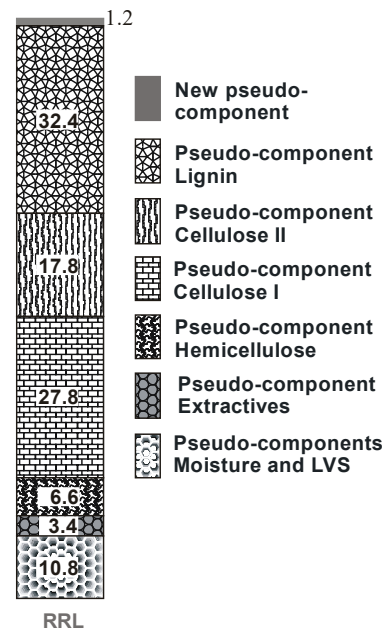

(b)

Figure 8. TGA and DTG curves (a) along with the results of deconvolution of the DTG curve (b) of RL and RRL samples.

In contrast to the RBL and RML samples, the RRL sample has a much lower mass loss than the RL sample in the temperature range above $225^{\circ} \mathrm{C}$ (Figure 8a). In the temperature range of $155-450{ }^{\circ} \mathrm{C}$, the RRL sample emits much fewer volatile products of pyrolysis compared to the RL sample. It follows from Figure $8 \mathrm{~b}$ that the extraction did not increase the yield in extractives but decreased the yield in moisture and LVS along with the thermal stability of hemicellulose pseudo-components by $23.2 \%$. The thermal stability of pseudocomponents of cellulose I and lignin increased substantially after the extraction.

The results presented in Figures 6-8 imply that some part of organic components that are present in the composition of volatile products during pyrolysis is removed from $\mathrm{BL}, \mathrm{RL}$, and ML samples during extraction. Although the studied leaves belong to lignocellulosic biomass, the extraction affects the loosening of structure and the thermal stability of its basic components in different ways and therefore the interactions taking place between these components. In turn, this means that during pyrolysis of initial samples of leaves and their after-extraction residues, the structural changes in these materials will take place in different ways.

Figure 9 presents the diffractograms of chars of leaves and their after-extraction residues pyrolyzed at a temperature of $450{ }^{\circ} \mathrm{C}$. In the diffractograms, there are visible reflexes from the biochars included in biochars of inorganic components and from the reflex of (002) $\mathrm{NaF}$. In this case $\mathrm{NaF}$ is used as an internal standard. With regard to $\mathrm{NaF}$ reflex, the differences in integral intensity of the reflex from the biochar of samples can be visually evaluated. Such differences point to the degree of ordering of pyrolyzed material. Based on the data in Table 2 and the results published in works [31,44], it can be suggested that the peaks in the diffractograms of biochars point to the presence of inorganic components in the form of quartz, calcite, K-feldspar, plagioclase feldspar, magnetite, etc. The shape of the reflex from biochar in the range of 2 theta 14-34 implies that, in biochar material, except in the amorphous phase, the occurrence of two types of ordering, $\gamma$-fraction and crystalline phase, can be expected. The presence of $\gamma$-fraction is caused by local molecular ordering of aliphatic or alicyclic chains whereas crystalline (graphite-like) phase is formed from lamellas that have a structure similar to graphene layers $[45,46]$. 


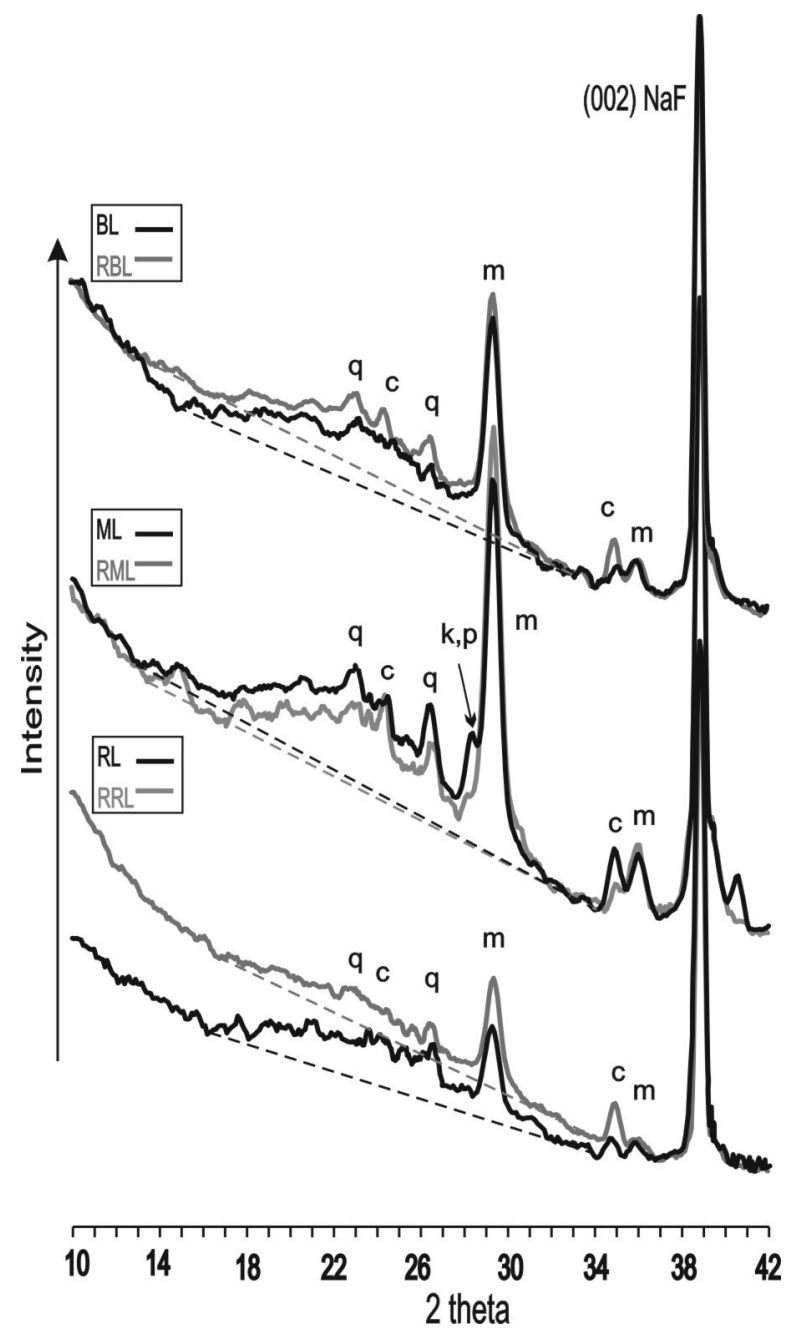

Figure 9. Diffractograms of pyrolyzed leaves and their pyrolyzed after-extraction residues: q-quartz, k-K-feldspar (e.g., microline), p—plagioclase feldspar (e.g., albite, anorthite), c—calcite, $\mathrm{m}-$ magnetite (magnetite and maghemite overlap).

The comparison of the diffractograms implies that the char of RML sample has the best degree of ordering. Compared to the diffractogram of ML sample, it has a smaller angle of deviation of the background line on the side of smaller 2 theta angles. The char of RRL sample is less ordered, its diffractogram has the greatest angle of deviation of the background line on the side of smaller 2 theta angles. Taking into account that the loosening of the structure of material facilitates its ordering, it can be suggested that a better ordering of char from the RML sample results from a decrease in thermal stability of hemicellulose, cellulose I, and cellulose II. The results of deconvolution of the DTG curve presented in Figure $7 \mathrm{~b}$ point to this. A worse ordering of the char of the RRL sample could have been caused only by a lower thermal stability of hemicellulose. The data in Figure $8 \mathrm{~b}$ imply that the pseudo-components of cellulose and lignin of the RRL sample increased their thermal stability. The ordering of the char of the RBL sample took the medium position because the pseudo-components of hemicellulose, cellulose I, and lignin reduced their thermal stability (see the results of deconvolution in Figure 6b).

The FT-IR spectra of samples were registered at different temperatures in order to evaluate the influence of extraction on the composition of volatile products of pyrolysis. Figure 10 presents the FT-IR spectra of volatile products of pyrolysis of BL and RBL samples. To make a contrastive analysis easier, the spectra were presented in such a way that the height of the $\mathrm{CO}_{2}$ band in them was the same. 


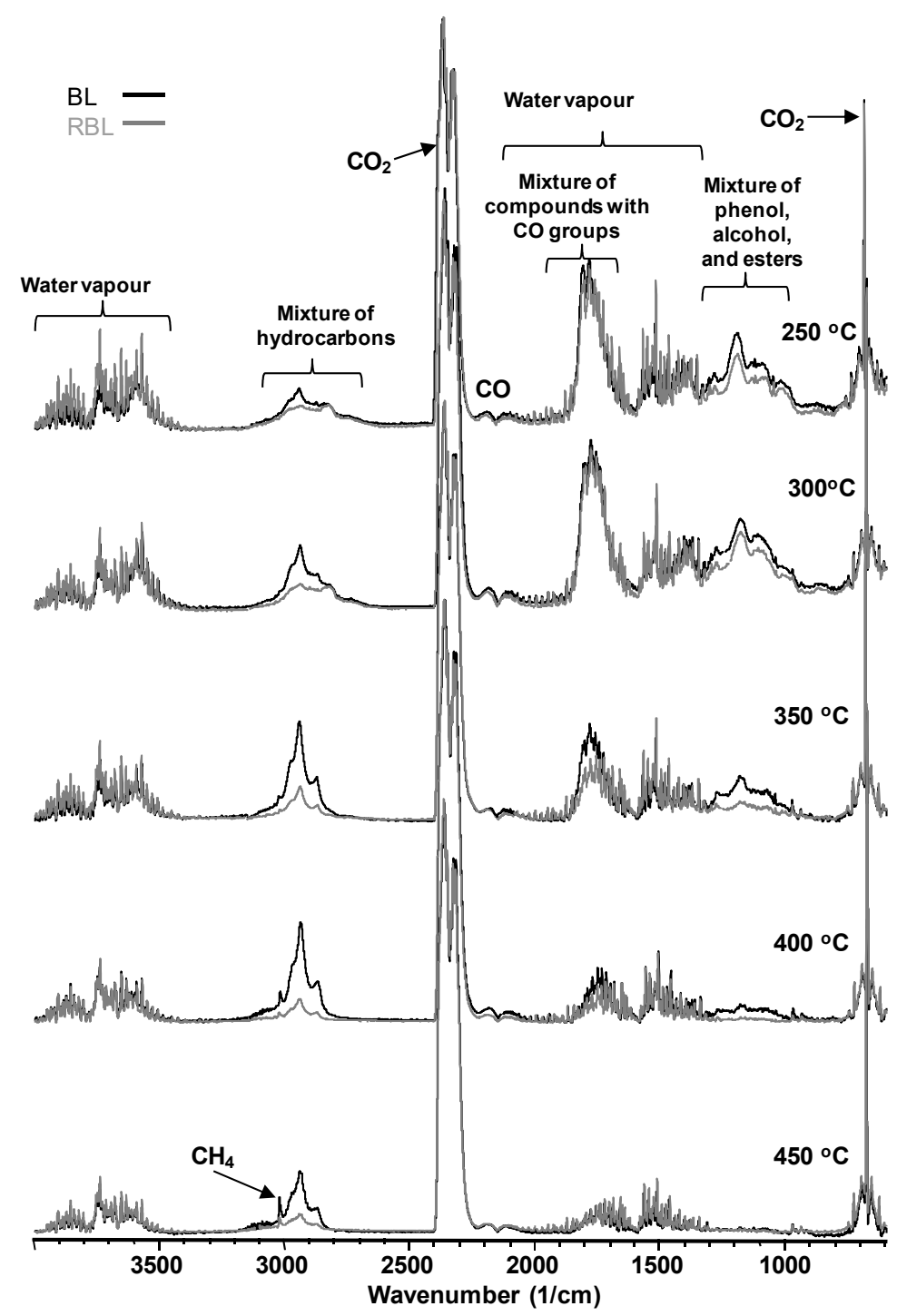

Figure 10. FT-IR spectra of volatile products emitted during pyrolysis of BL and RBL samples.

It follows from the analysis of the shape of the FT-IR spectra of volatile products in Figure 10 that during pyrolysis of the after-extraction residues of birch leaves there are much lower contribution ratios of a mixture of saturated and unsaturated hydrocarbons, a mixture of compounds containing carbonyl groups, and a mixture of alcohols, phenols, and esters formed as a result of defragmentation of the $\beta$-1,4-glicoside bond observed in the composition of volatile products. Such a shape of the spectra proves that during extraction a significant part of the aforementioned compounds (over 20\%) was extracted from birch leaves.

Somehow, less material (about 17\%) was extracted from the ML and RL samples. It was expected that the transformation of the shape of the spectra of volatiles from these samples, which was caused by extraction, would take place in similar way. However, it follows from the shape of the spectra in Figure 11 that, in the case of the ML and RML samples, the differences in shape are visible in the FT-IR spectra of volatile products that were emitted in the temperature range of $300-400^{\circ} \mathrm{C}$. In the composition of volatile products of the RML sample (like RBL sample), there is an increased contribution ratio of water vapour and a decreased contribution ratio of saturated and unsaturated hydrocarbons. 


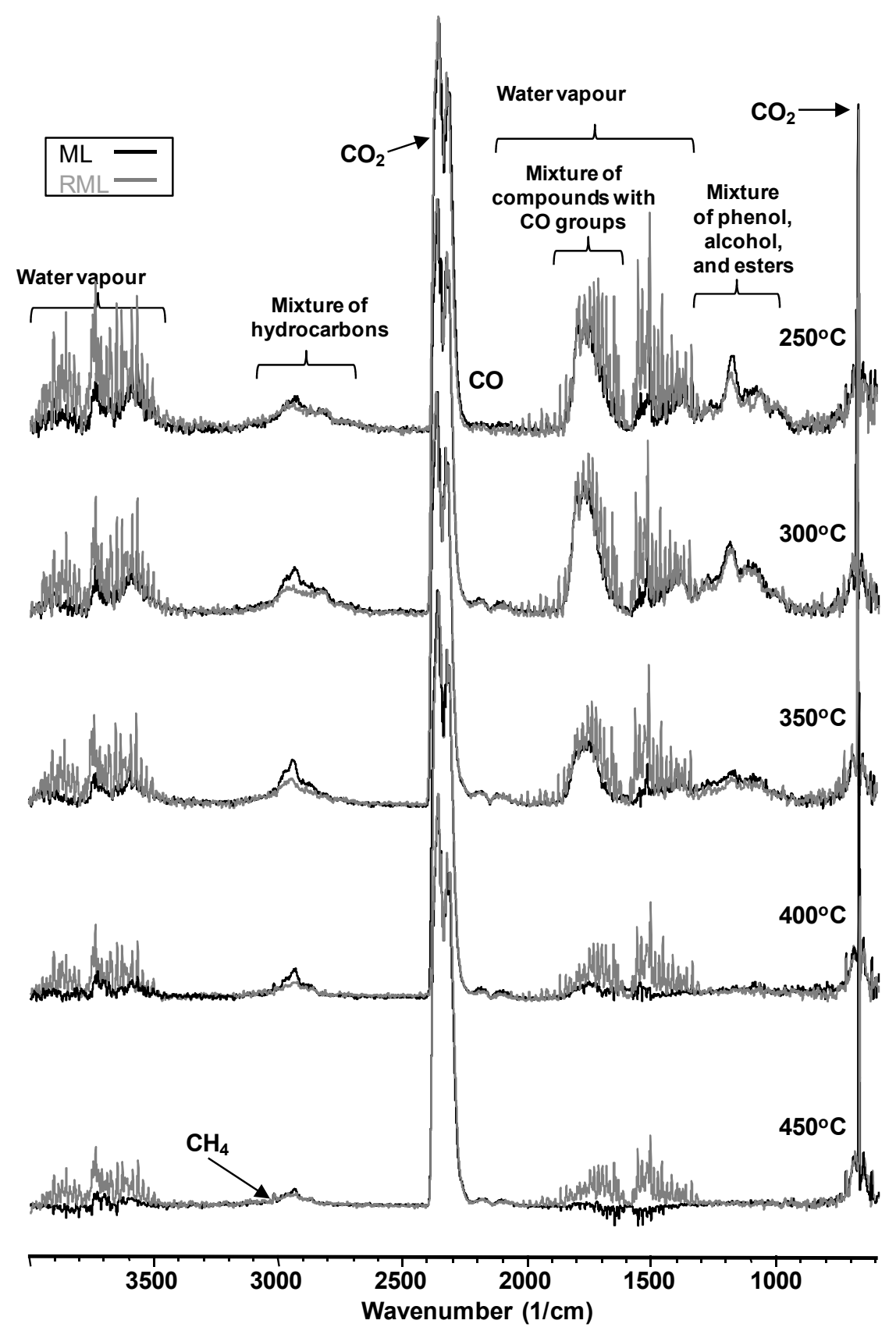

Figure 11. FT-IR spectra of volatile products emitted during pyrolysis of ML and RML samples.

No increase in the contribution ratio of water vapour was observed in the volatile products of pyrolysis of the RRL sample. There is a visible decrease in the contribution ratio of saturated and unsaturated hydrocarbons in the temperature range of $300-450{ }^{\circ} \mathrm{C}$ and a tendency toward a decrease in the contribution ratio of the mixture of compounds with carbonyl groups in the temperature range of $250-400^{\circ} \mathrm{C}$. Attention should be drawn to the shape of fragments of the spectrum in the range of wavenumbers corresponding to the occurrence of bands of water vapour at the temperatures of $350-450{ }^{\circ} \mathrm{C}$ (Figure 12). This shape may have been caused by the interactions of water vapour with the surface of formed char, and a decrease in its contribution ratio was observed as a result. It cannot be excluded that these interactions of water vapour with the surface of char could have been catalysed by inorganic components present on the char surface. The peaks on the diffractograms of chars point to the presence of these inorganic components [47]. 


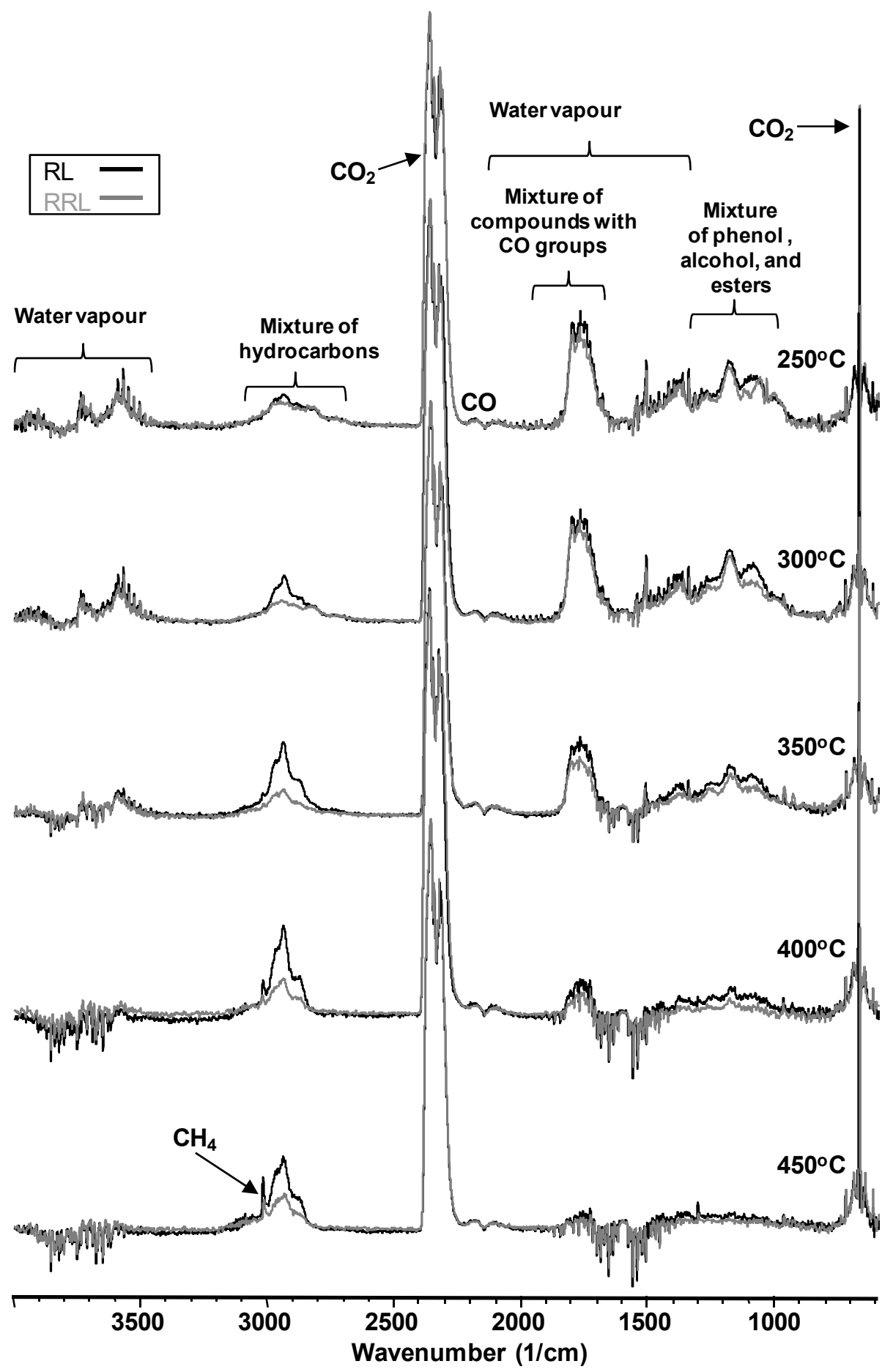

Figure 12. FT-IR spectra of volatile products emitted during pyrolysis of RL and RRL samples.

The FT-IR spectra of volatile products of RL and RRL samples show some differences starting at a temperature of $300^{\circ} \mathrm{C}$ (Figure 12).

\section{Conclusions}

The leaves of urban trees falling in autumn should be utilized. The research on the course of the pyrolysis process of leaves (as the first step of the combustion process) has proven that leaves can be subjected to combustion after the extraction operation. The advantages of such an approach are as follows: 
(i) The yield of extraction of birch, maple, and rowan leaves is $22.12 \pm 0.20 \%, 17.20 \pm 0.03 \%$, and $17.78 \pm 1.30 \%$, respectively.

(ii) The removal of such an amount of material reduces the burden on the environment caused by dangerous chemical compounds present in the composition of volatile products of pyrolysis (aromatic hydrocarbons, compounds with carbonyl groups, alcohols, phenols, water vapour).

(iii) The composition of extracted material has greater homogeneity in groups of compounds with carbonyl chromophore groups compared to the composition of the condensate that is formed during pyrolysis.

(iv) The separation of extracted material into fractions will enrich the raw material platform with materials that can be used to obtain phytochemicals and other chemical reagents.

(v) The removal of dangerous compounds from the material of leaves will increase the amount of energy resources that can be solely subjected to combustion or added to other species of combusted biomass.

Author Contributions: Conceptualization, V.Z.; methodology, V.Z.; investigation, V.Z., A.S. and M.B.; data curation, V.Z., A.S. and M.B., resources, A.S.; validation, A.S.; writing-original draft preparation, V.Z.; writing-review and editing, V.Z.; project administration, V.Z. and A.S.; funding acquisition, A.S. All authors have read and agreed to the published version of the manuscript.

Funding: This research was funded by Rector of Jan Kochanowski University in Kielce, grant number SIGR.RN.20.078.611.

Institutional Review Board Statement: Not applicable.

Informed Consent Statement: Not applicable.

Data Availability Statement: Not applicable.

Conflicts of Interest: The authors declare no conflict of interest.

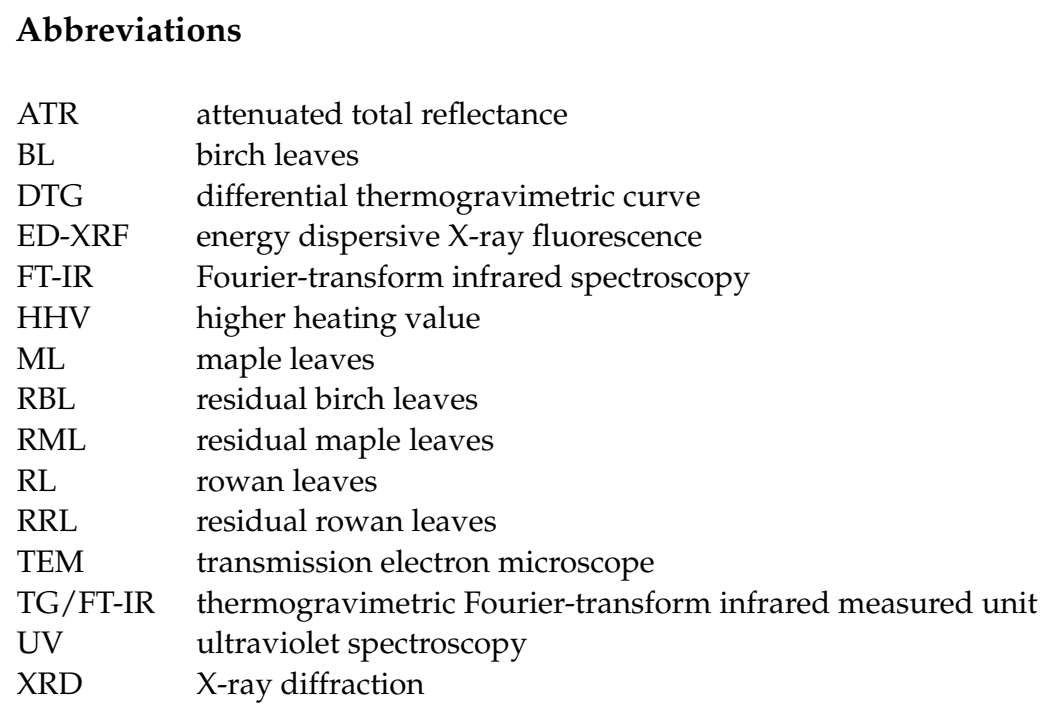

\section{References}

1. Tálos-Nebehaj, E.; Hofmann, T.; Albert, L. Seasonal changes of natural antioxidant content in the leaves of Hungarian forest trees. Ind. Crop. Prod. 2017, 98, 53-59. [CrossRef]

2. Taamalli, A.; Sánchez, J.L.; Jebabli, H.; Trabelsi, N.; Abaza, L.; Carretero, A.S.; Cho, J.Y.; Román, D.A. Monitoring the Bioactive Compounds Status in Olea europaea According to Collecting Period and Drying Conditions. Energies 2019, 12, 947. [CrossRef]

3. He, M.; Mourant, D.; Gunawan, R.; Lievens, C.; Wang, X.S.; Ling, K.; Bartle, J.; Li, C.-Z. Yield and properties of bio-oil from the pyrolysis of mallee leaves in a fluidised-bed reactor. Fuel 2012, 102, 506-513. [CrossRef]

4. Mythili, R.; Venkatachalam, P.; Subramanian, P.; Uma, D. Characterization of bioresidues for biooil production through pyrolysis. Bioresour. Technol. 2013, 138, 71-78. [CrossRef] 
5. Singh, J.; Kaur, S.; Lee, J.; Mehta, A.; Kumar, S.; Kim, K.-H.; Basu, S.; Rawat, M. Highly fluorescent carbon dots derived from Mangifera indica leaves for selective detection of metal ions. Sci. Total. Environ. 2020, 720, 137604. [CrossRef] [PubMed]

6. Cai, W.; Zhou, Q.; Xie, Y.; Liu, J.; Long, G.; Cheng, S.; Liu, M. A direct carbon solid oxide fuel cell operated on a plant derived biofuel with natural catalyst. Appl. Energy 2016, 179, 1232-1241. [CrossRef]

7. Raghuvansi, S.K.S.; Prasad, R.; Mishra, A.S.; Chaturvedi, O.H.; Tripathi, M.K.; Misra, A.K.; Jakhmola, R.C.; Saraswat, B.L.; Jakhmola, R.C. Effect of inclusion of tree leaves in feed on nutrient utilization and rumen fermentation in sheep. Bioresour. Technol. 2007, 98, 511-517. [CrossRef]

8. Bilba, K.; Arsene, M.; Ouensanga, A. Study of banana and coconut fibers: Botanical composition, thermal degradation and textural observations. Bioresour. Technol. 2007, 98, 58-68. [CrossRef]

9. Wang, R.; Wang, P.; Yan, X.; Lang, J.; Peng, C.; Xue, Q. Promising Porous Carbon Derived from Celtuce Leaves with Outstanding Supercapacitance and $\mathrm{CO}_{2}$ Capture Performance. ACS Appl. Mater. Interfaces 2012, 4, 5800-5806. [CrossRef]

10. Zhu, X.; Yu, S.; Xu, K.; Zhang, Y.; Zhang, L.; Lou, G.; Wu, Y.; Zhu, E.; Chen, H.; Shen, Z.; et al. Sustainable activated carbons from dead ginkgo leaves for supercapacitor electrode active materials. Chem. Eng. Sci. 2018, 181, 36-45. [CrossRef]

11. Wang, Q.; Zhang, Y.; Xiao, J.; Jiang, H.; Hu, T.; Meng, C. Copper oxide/cuprous oxide/hierarchical porous biomass-derived carbon hybrid composites for high-performance supercapacitor electrode. J. Alloys Compd. 2019, 782, 1103-1113. [CrossRef]

12. Wei, X.; Li, Y.; Gao, S. Biomass-derived interconnected carbon nanoring electrochemical capacitors with high performance in both strongly acidic and alkaline electrolytes. J. Mater. Chem. A 2017, 5, 181-188. [CrossRef]

13. Kalamdhad, A.S.; Singh, Y.K.; Ali, M.; Khwairakpam, M.; Kazmi, A.A. Rotary drum composting of vegetable waste and tree leaves. Bioresour. Technol. 2009, 100, 6442-6450. [CrossRef]

14. Moharana, P.C.; Biswas, D.R. Assessment of maturity indices of rock phosphate enriched composts using variable crop residues. Bioresour. Technol. 2016, 222, 1-13. [CrossRef] [PubMed]

15. Shahid, M.; Dumat, C.; Khalid, S.; Schreck, E.; Xiong, T.; Niazi, N.K. Foliar heavy metal uptake, toxicity and detoxification in plants: A comparison of foliar and root metal uptake. J. Hazard. Mater. 2017, 325, 36-58. [CrossRef]

16. Yalaltdinova, A.; Kim, J.; Baranovskaya, N.; Rikhvanov, L. Populus nigra L. as a bioindicator of atmospheric trace element pollution and potential toxic impacts on human and ecosystem. Ecol. Indic. 2018, 95, 974-983. [CrossRef]

17. Pourkhabbaz, A.; Rastin, N.; Olbrich, A.; Langenfeld-Heyser, R.; Polle, A. Influence of Environmental Pollution on Leaf Properties of Urban Plane Trees, Platanus orientalis L. Bull. Environ. Contam. Toxicol. 2010, 85, 251-255. [CrossRef]

18. Alaimo, M.G.; Varrica, D. Recognition of Trace Element Contamination Using Ficus macrophylla Leaves in Urban Environment. Int. J. Environ. Res. Public Health 2020, 17, 881. [CrossRef]

19. Oo, H.M.; Karin, P.; Chollacoop, N.; Hanamura, K. Physicochemical characterization of forest and sugarcane leaf combustion's particulate matters using electron microscopy, EDS, XRD and TGA. J. Environ. Sci. 2021, 99, 296-310. [CrossRef] [PubMed]

20. Makkawi, Y.; El Sayed, Y.; Salih, M.; Nancarrow, P.; Banks, S.; Bridgwater, T. Fast pyrolysis of date palm (Phoenix dactylifera) waste in a bubbling fluidized bed reactor. Renew. Energy 2019, 143, 719. [CrossRef]

21. Enes, T.; Aranha, J.; Fonseca, T.; Lopes, D.; Alves, A.; Lousada, J. Thermal Properties of Residual Agroforestry Biomass of Northern Portugal. Energies 2019, 12, 1418. [CrossRef]

22. Regueiro, A.; Jezerská, L.; Pérez-Orozco, R.; Patiño, D.; Zegzulka, J.; Nečas, J. Viability Evaluation of Three Grass Biofuels: Experimental Study in a Small-Scale Combustor. Energies 2019, 12, 1352. [CrossRef]

23. Zhao, F.; Shu, L.; Wang, Q.; Wang, M.; Tian, X. Emissions of volatile organic compounds from heated needles and twigs of Pinus pumila. J. For. Res. 2011, 22, 243-248. [CrossRef]

24. Samae, H.; Tekasakul, S.; Tekasakul, P.; Furuuchi, M. Emission factors of ultrafine particulate matter $(\mathrm{PM}<0.1 \mu \mathrm{m})$ and particlebound polycyclic aromatic hydrocarbons from biomass combustion for source apportionment. Chemosphere 2021, 262, 127846. [CrossRef]

25. Li, W.; Shao, L. Transmission electron microscopy study of aerosol particles from the brown hazes in northern China. J. Geophys. Res. Space Phys. 2009, 114, 1-10. [CrossRef]

26. Davis, J.; Tiwari, K.; Novosselov, I. Soot morphology and nanostructure in complex flame flow patterns via secondary particle surface growth. Fuel 2019, 245, 447-457. [CrossRef]

27. Chang, Q.; Gao, R.; Gao, M.; Yu, G.; Wang, F. The structural evolution and fragmentation of coal-derived soot and carbon black during high-temperature air oxidation. Combust. Flame 2020, 216, 111-125. [CrossRef]

28. Li, D.; Li, W.; Chen, H.; Li, B. The adjustment of hydrogen bonds and its effect on pyrolysis property of coal. Fuel Process. Technol. 2004, 85, 815-825. [CrossRef]

29. Fang-Jing, L.; Wei, X.Y.; Zong, Z.-M.; Fan, M. Characterization of the oxygenated chemicals produced from supercritical methanolysis of modified lignites. Energy Fuels 2016, 30, 2636-2646. [CrossRef]

30. Lazdovica, K.; Kampars, V.; Liepina, L.; Vilka, M. Comparative study on thermal pyrolysis of buckwheat and wheat straws by using TGA-FTIR and Py-GC/MS methods. J. Anal. Appl. Pyrolysis 2017, 124, 1-15. [CrossRef]

31. Zubkova, V.; Strojwas, A.; Bielecki, M.; Kieush, L.; Koverya, A. Comparative study of pyrolytic behavior of the biomass wastes originating in the Ukraine and potential application of such biomass. Part 1. Analysis of the course of pyrolysis process and the composition of formed products. Fuel 2019, 254, 115688. [CrossRef]

32. Traoré, M.; Kaal, J.; Matínez Cortizas, A. Application of FTIR spectroscopy to the characterization of archeological wood. Spectrochim. Acta Part A Mol. Biomol. Spectrosc. 2016, 153, 63-70. [CrossRef] 
33. Zhao, X.-B. Peracetic acid pretreatment of sugarcane bagasse for enzymatic hydrolysis: A continued work. J. Chem. Technol. Biotechnol. 2008, 6, 950-956. [CrossRef]

34. Rao, C.N.R. Ultra-Violet and Visible Spectroscopy. Chemical Applications; Butterworth and Co (Publishers) Ltd.: London, UK, 1975; pp. 58-62.

35. Ramos-Carmona, S.; Martínez, J.D.; Pérez, J.F. Torrefaction of patula pine under air conditions: A chemical and structural characterization. Ind. Crop. Prod. 2018, 118, 302-310. [CrossRef]

36. Coates, J. Interpretation of Infrared Spectra, A Practical Approach. In Encyclopedia of Analytical Chemistry; Meyers, R.A., Ed.; John Wiley and Sons Ltd.: Chichester, UK, 2000; pp. 10815-10837.

37. Yang, H.; Yan, R.; Chen, H.; Lee, D.H.; Zheng, C. Characteristics of hemicellulose, cellulose and lignin pyrolysis. Fuel 2007, 86, 1781-1788. [CrossRef]

38. Yang, H.; Yan, R.; Chen, H.; Zheng, C.; Lee, D.H.; Liang, D.T. In-Depth Investigation of Biomass Pyrolysis Based on Three Major Components: Hemicellulose, Cellulose and Lignin. Energy Fuels 2006, 20, 388-393. [CrossRef]

39. Wu, S.; Shen, D.; Hu, J.; Zhang, H.; Xiao, R. Cellulose-lignin interactions during fast pyrolysis with different temperatures and mixing methods. Biomass Bioenergy 2016, 90, 209-217. [CrossRef]

40. Hosoya, T.; Kawamoto, H.; Saka, S. Cellulose-hemicellulose and cellulose-lignin interactions in wood pyrolysis at gasification temperature. J. Anal. Appl. Pyrolysis 2007, 80, 118-125. [CrossRef]

41. Liu, Q.; Zhong, Z.; Wang, S.; Luo, Z. Interactions of biomass components during pyrolysis: A TG-FTIR study. J. Anal. Appl. Pyrolysis 2011, 90, 213-218. [CrossRef]

42. Hu, J.; Jiang, B.; Liu, J.; Sun, Y.; Jiang, X. Influence of interactions between biomass components on physicochemical characteristics of char. J. Anal. Appl. Pyrolysis 2019, 144, 104704. [CrossRef]

43. Wang, M.; Tian, J.; Roberts, D.G.; Chang, L.; Xie, K. Interactions between corncob and lignite during temperature-programmed co-pyrolysis. Fuel 2015, 142, 102-108. [CrossRef]

44. Lei, S.; Shi, Y.; Qiu, Y.; Che, L.; Xue, C. Performance and mechanisms of emerging animal-derived biochars for immobilization of heavy metals. Sci. Total. Environ. 2019, 646, 1281-1289. [CrossRef] [PubMed]

45. Siddiqui, M.N.; Ali, M.F.; Shirokoff, J. Use of X-ray diffraction in assessing the aging pattern of asphalt fractions. Fuel 2002, 81, 51-58. [CrossRef]

46. AlHumaidan, F.S.; Hauser, A.; Rana, M.S.; Lababidi, H.M.S.; Behbehani, M. Changes in asphaltene structure during thermal cracking of residual oils: XRD study. Fuel 2015, 150, 558-564. [CrossRef]

47. Couhert, C.; Commandre, J.-M.; Salvador, S. Is it possible to predict gas yields of any biomass after rapid pyrolysis at high temperature from its composition in cellulose, hemicellulose and lignin? Fuel 2009, 88, 408-417. [CrossRef] 